\title{
Paleointensity estimates from oceanic gabbros: Effects of hydrothermal alteration and cooling rate
}

\author{
Yoichi Usui \\ Institute for Research on Earth Evolution, Japan Agency for Marine-Earth Science and Technology, \\ 2-15 Natsushima-cho, Yokosuka, Kanagawa 2370061, Japan \\ (Received January 10, 2013; Revised March 20, 2013; Accepted March 26, 2013; Online published October 9, 2013)
}

\begin{abstract}
Gabbros recovered by previous ocean drillings were investigated in paleointensity and rock magnetic experiments. The young ages of the samples (ca. 0.78-1.3 Ma) enable a direct comparison between the plutonic paleointensity and volcanic data. Microscopic observations revealed two kinds of magnetite: needle-shaped exsolution in plagioclase and aggregate associated with the hydrothermal alteration of olivine. In Shaw paleointensity experiments, some samples revealed reasonable estimates, while some others showed an anomalously low ratio of natural remanent magnetization (NRM) versus thermoremanent magnetization (TRM). First-order reversal curve (FORC) diagrams indicated that the reasonable NRM/TRM were from non-interacting single domain magnetite exsolved in plagioclase, while the anomalously low NRM/TRM were from secondary magnetite associated with olivine. From the paleointensity results, the mean virtual axial dipole moment (VADM) was calculated to be $8.2 \pm 2.1\left[10^{22} \mathrm{Am}^{2}\right]$. Volcanic records in the PINT database for 0.78-1.3 Ma revealed a mean virtual dipole moment (VDM) of $6.3 \pm 0.73\left[10^{22} \mathrm{Am}^{2}\right]$. The difference between them is consistent with the theoretical prediction of the cooling rate effect on paleointensity. These results indicate that oceanic gabbros are reliable paleointensity recorders.
\end{abstract}

Key words: Paleomagnetism, paleointensity, exsolved magnetite, cooling rate effect, oceanic gabbro, Ocean Drilling Program, Integrated Ocean Drilling Program.

\section{Introduction}

Past geomagnetic field intensity (paleointensity) provides important information to constrain the deep Earth dynamics and evolution. For paleointensity studies, it is crucial to test the fidelity of various rock types as paleointensity recorders. The fidelity of lavas have been confirmed by comparing paleointensity estimates from historical lavas with a known field intensity (e.g., Coe and Grommé, 1973; Oishi et al., 2005), although actual paleointensity reconstruction is far from trivial due to the complexity of natural materials. Unfortunately, lavas are prone to weathering, so fresh samples are difficult to obtain for the geological past. Consequently, many high-quality paleointensity data for the Precambrian originate from plutonic rocks (Tarduno et al., 2007; Selkin et al., 2008; Donadini et al., 2011). Nonetheless, the fidelity of plutonic rocks as paleointensity recorders remains unclear, as the long cooling times of plutonic rocks prevents a direct comparison with a known intensity.

To assess the fidelity of plutonic rocks as paleointensity recorders, paleointensity and rock magnetic experiments have been conducted on oceanic gabbros. The samples were recovered by previous ocean drillings. Their young ages (ca. 0.78-1.3 Ma) have enabled a direct comparison of the paleointensity estimates derived from them with those from

Copyright (C) The Society of Geomagnetism and Earth, Planetary and Space Sciences (SGEPSS); The Seismological Society of Japan; The Volcanological Society of Japan; The Geodetic Society of Japan; The Japanese Society for Planetary Sciences; TERRAPUB.

doi:10.5047/eps.2013.03.015 volcanic materials. Using the volcanic data as reference, the fidelity of plutonic paleointensity was tested. Specifically, two major problems associated with plutonic paleointensity investigations are addressed in this paper: the cooling rate effect and hydrothermal alteration.

The cooling rates differ significantly between laboratory experiments (samples cool in 20-30 minutes) and plutonic rocks (cool in thousands to millions of years). Single domain (SD) theory predicts $\sim 3-7 \%$ change in magnetization per one order of magnitude change in cooling rate, with a slower cooling resulting in stronger magnetization (Dodson and McClelland-Brown, 1980; Halgedahl et al., 1980). This should correlate to the same amount of bias in paleointensity estimates. This prediction was directly tested in control experiments by changing the cooling time between a few minutes to tens of hours, and the prediction was generally supported, but with a large sample-to-sample variation of a factor of 3-5 (Fox and Aitken, 1980; Chauvin et al., 2000; Genevey and Gallet, 2002; Leonhardt et al., 2006; Ferk et al., 2010; Yu, 2011). For plutonic rocks, the theory predicts that the paleointensity estimate will overestimate the true field by $\sim 30-60 \%$, and it has become common to use these values as correction factors (e.g., Tarduno et al., 2007; Selkin et al., 2008; Donadini et al., 2011). However, the large sample-to-sample variation observed in the control experiments, if extrapolated, implies very large uncertainties in an actual overestimate. Besides, only a few plutonic rocks contain solely SD magnetic grains, and larger pseudosingle domain (PSD) grains are the major carriers of paleo- 

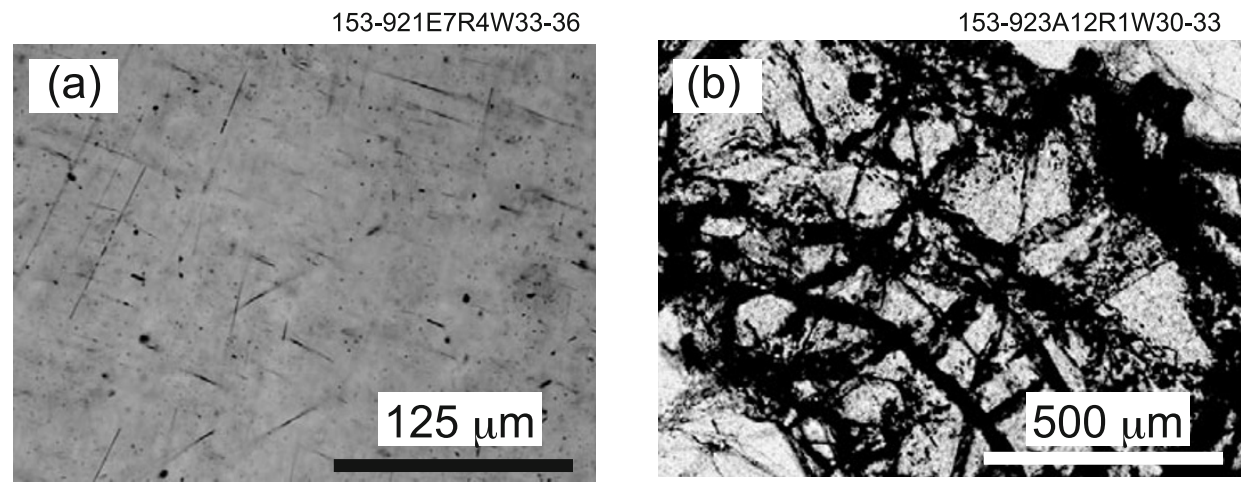

Fig. 1. Microscopic images of the occurrences of magnetite. (a) Needle-shaped magnetite (black) in plagioclase. (b) Magnetite aggregate (black) associated with the hydrothermal alteration of olivine.

magnetic information. Winklhofer et al. (1997) argued that some magnetic grains near the SD/PSD size boundary can have a cooling rate bias that is opposite in sign to SD grains on the basis of micromagnetic simulations. Yu (2011) experimentally showed that the cooling rate effect for PSD grains is less significant than that for SD grains. Irrespective of these uncertainties, the cooling time of plutonic rocks is unattainable in the laboratory, and direct tests of the cooling rate effect on paleointensity are impossible. Comparison between young oceanic gabbros with volcanic estimates could constrain the cooling rate effect.

Another challenge in paleointensity studies of plutonic rocks is hydrothermal alteration due to the long cooling time. Hydrothermal alteration of mafic minerals produces secondary magnetic minerals that could contaminate the paleointensity record. Targeted measurements of magnetic inclusions in silicate crystals may exclude the contamination (Cottrell and Tarduno, 1999; Tarduno et al., 2006). Several studies have shown that plagioclase or clinopyroxene in some plutonic rocks contain tiny, exsolved magnetite inclusions which are near stoichiometric and magnetically stable (Davies, 1981; Feinberg et al., 2005; Usui et al., 2006). However, the strong texture of such a magnetite within a host mineral produces a large magnetic anisotropy (Feinberg et al., 2006). This makes paleointensity experiments using single silicate crystals difficult when they contain exsolved magnetite (Usui and Nakamura, 2009), whilst a nearrandom texture of host minerals would reduce the magnetic anisotropy at a whole rock scale (Usui et al., 2006). If one uses whole rock samples, it is necessary to discriminate samples whose magnetic signals are dominated by secondary magnetic minerals. However, secondary magnetite formed after the hydrothermal alteration of whole rock samples could also be near stoichiometric and magnetically stable (Kikawa and Ozawa, 1992; Usui and Yamazaki, 2010), and rock magnetic criteria to distinguish secondary magnetite is uncertain.

\section{Samples}

\subsection{Geological background}

I have used gabbro samples recovered by ODP Leg 153 and IODP Expedition 304/305. Both of the cruises drilled sites near the slow-spreading Mid-Atlantic Ridge. Leg 153 (Cannat et al., 1995) recovered gabbroic rocks from four sites (Site 921-924). The drill holes were relatively shallow with a penetration ranging from 14 to $82 \mathrm{~m}$ below seafloor (mbsf). Major rock types are gabbro and olivine gabbro. Lineated sea surface magnetic anomalies suggest a nominal age of $\sim 1$ Ma for the drill sites (Schulz et al., 1988). Previous paleomagnetic studies revealed that the samples showed some drilling-induced overprint, and that the maximum unblocking temperatures are near $580^{\circ} \mathrm{C}$ (Gee et al., 1995; Gee and Meurer, 2002), indicating the presence of nearstoichiometric magnetite. Up to three magnetic components, besides the drilling-induced overprint, were observed in some samples (Gee et al., 1995; Gee and Meurer, 2002). Gee and Meurer (2002) interpreted them as thermoremanence recorded in successive polarity intervals of $\sim 1.07-$ $0.99 \mathrm{Ma}$ (Jaramillo normal polarity interval), 0.9-0.78 Ma (the Matuyama reversed polarity interval), and $0.78 \mathrm{Ma}$ to present (the Brunhes normal polarity interval).

Expedition 304/305 (Blackman et al., 2006, 2011) recovered gabbroic rocks mainly from Hole U1309D which penetrated 1400 mbsf. Direct U-Pb zircon dating revealed ages of $1.17 \pm 0.2 \mathrm{Ma}$ for $0-600 \mathrm{mbsf}$ and $1.24 \pm 0.02 \mathrm{Ma}$ for 600-1415 mbsf (Grimes et al., 2008) that are slightly younger than the nominal age estimated from sea surface magnetic anomalies (1.5-2 Ma; Blackman et al., 2006, 2011). Similarly to the Leg 153 gabbros, previous paleomagnetic studies revealed that the majority of the samples showed some drilling-induced overprint, and that maximum unblocking temperatures are near $580^{\circ} \mathrm{C}$ (Zhao and Tominaga, 2009).

I obtained oriented minicores and cubes, avoiding zones where intense alteration had been noted previously (Cannat et al., 1995; Blackman et al., 2006). Magnetically strong oxide gabbros were also avoided, because such rocks have been reported to be magnetically less stable (Pariso and Johnson, 1993) and likely to be less suited for paleointensity experiments. The total number of analyzed samples was 30. The samples were gabbro or olivine gabbro. From each sample, a small slice was cut for a thin section and rock magnetic experiments, and the remainder was used in paleointensity experiments.

\subsection{Optical mineralogy of magnetic minerals}

On thin sections, large opaque grains that crystallized directly from the melt were rare. Two main occurrences of magnetic minerals were found. One was opaque nee- 
dles in plagioclase (Fig. 1(a)). This occurrence was similar to magnetite exsolved in plagioclase in other oceanic gabbros (Davies, 1981). The other occurrence was magnetite associated with the hydrothermal alteration of olivine (Fig. 1(b)). The extent of hydrothermal alteration of olivine varied within a sample as well as from one sample to another; thus, it was difficult to quantify the amount of magnetite associated with olivine from thin section observations alone. Clinopyroxene in my samples did not contain a significant amount of opaque minerals.

\section{Method}

The Shaw paleointensity method (Shaw, 1974) was employed, which is based on alternating field (AF) demagnetization. AF demagnetization was performed using either a three-axis sample tumbling demagnetizer DEM-95 (Natsuhara Giken Co., Ltd.) or an in-line demagnetizer of cryogenic magnetometers (2G Enterprises). I demagnetized at 2,5 or $10 \mathrm{mT}$ intervals up to a peak field of $150 \mathrm{mT}$ (for samples demagnetized with DEM-95) or $100 \mathrm{mT}$ (for samples demagnetized with the in-line demagnetizer). Some samples were demagnetized using both the in-line demagnetizer and DEM-95; first they were demagnetized up to $100 \mathrm{mT}$ using the in-line demagnetizer, and then further demagnetized from 110 to $150 \mathrm{mT}$ using DEM-95. The maximum AF demagnetization does not necessarily erase all the remanence, so the remanence remaining after the maximum demagnetization step was subtracted from the remanence measured at each demagnetization step. The paleointensity was estimated by comparing AF decay curves of the natural remanent magnetization (NRM) and the total thermoremanent magnetization (TRM) on an NRM-TRM diagram. A spinner magnetometer ASPIN (Natsuhara Giken Co., Ltd.), or a cryogenic magnetometers Model 760 (2G Enterprises), was used to measure magnetization. To impart total TRM, I used an applied field of $30 \mu \mathrm{T}$ and a heating temperature of $600^{\circ} \mathrm{C}$ with a holding time of 15 minutes using a thermal demagnetization oven TDS-1 (Natsuhara Giken Co., Ltd.). The above instruments were hosted in a magnetically-shielded room at JAMSTEC Yokosuka HQ. The thermal alteration of the samples during experiments was checked by comparing the AF demagnetization of anhysteretic remanent magnetization (ARM) before and after the heating. These two ARMs are referred to as ARM1 and ARM2, respectively. To impart ARM, I used a DC bias field of $70 \mu \mathrm{T}$ and the maximum AF field used in the Shaw experiments (100 or $150 \mathrm{mT})$. As shown below, only a little alteration was detected for most of the samples, so I used the original version of the Shaw method, and did not employ corrections (Kono, 1978; Rolph and Shaw, 1985). The following criteria were applied to select successful results (after Yamamoto and Tsunakawa, 2005):

1) The primary component of NRM is recognized.

2) A linear portion $(R \geq 0.995)$ in the NRM-TRM diagram exists. That should consist of the primary component, and should not be less than $15 \%$ of the original NRM intensity.

3) The portion in the ARM1-ARM2 diagram corresponding to the linear portion in the NRM-TRM diagram is also linear $(R \geq 0.995)$. Its slope should be unity within $5 \%$.

4) The primary component and linear portions in both the NRM-TRM and the ARM1-ARM2 diagrams should include the maximum AF demagnetization step.

To correct for the effect of anisotropy on paleointensity estimates (Selkin et al., 2000), the anisotropy of partial ARM was measured on samples that were successful in the paleointensity experiments. Selkin et al. (2000) reported that the anisotropy of ARM imparted with a high peak AF field reasonably approximated the anisotropy of the total TRM. Because the Shaw method uses only the high coercivity part of NRM and TRM, the anisotropy of the partial ARM of the corresponding coercivity window was used. I imparted a partial ARM in two steps (Trindade et al., 2001): first I imparted total ARM with the maximum AF field used in the Shaw experiments (100 or $150 \mathrm{mT}$ ), then I demagnetized the low coercivity fraction that was not used in the paleointensity estimation. Anisotropy tensors were calculated using the body-diagonal seven-orientation scheme (Borradaile and Stupavsky, 1995) with three-axis measurements. At each orientation, residual magnetization after 100 or $150 \mathrm{mT}$ AF demagnetization was measured and subtracted from the partial ARM. The anisotropy tensors were evaluated using Jelinek's (1981) parameters.

Further tests were conducted on the successful samples. To check if the laboratory TRM is really a total TRM, I imparted a second TRM (TRM2) on the same samples, after the anisotropy experiments, using a holding time of 30 minutes. The AF decay curves of the first TRM and TRM2 were compared. To test thermal stability, high temperature susceptibility measurements were carried out using a kappabridge KLY-4 (AGICO). Rock powder made from unheated chips was heated up to $600^{\circ} \mathrm{C}$ in air.

Hysteresis measurements were carried out using a vibrating sample magnetometer (VSM) Model 3900 (Princeton Measurements Corporation) in JAMSTEC Yokosuka HQ. Rock powder of $\sim 150 \mathrm{mg}$ weight from each sample was prepared and packed in a gelatin capsule for measurements. The major hysteresis loop was measured for all samples. The saturation magnetization $\left(M_{\mathrm{s}}\right)$, saturation remanence $\left(M_{\mathrm{rs}}\right)$, coercivity $\left(H_{\mathrm{c}}\right)$ and coercivity of remanence $\left(H_{\mathrm{cr}}\right)$ were determined. For selected samples, I also measured first order reversal curves (FORCs) and calculated FORC diagrams (Pike et al., 1999; Roberts et al., 2000) using the software FORCinel (Harrison and Feinberg, 2008). FORC diagrams assess the distribution of microcoercivity and interaction field (Pike et al., 1999; Roberts et al., 2000; Carvallo et al., 2004). In addition, in order to examine the origin of the bulk magnetic characterization, mineral separates from selected samples were measured using alternating gradient field magnetometers (AGFM) model 2900 (Princeton Measurements Corporation) at the Kochi Core Center. Because hydrothermally altered olivine grains were fragile, they could not be extracted efficiently by crushing rocks. Thin sections were prepared and specific minerals were cut out under a binocular microscope using a non-magnetic diamond blade. In this procedure, glue was attached to the extracted minerals, so the precise weight of the mineral sep- 
(a)

305-1309D276R1W68-71

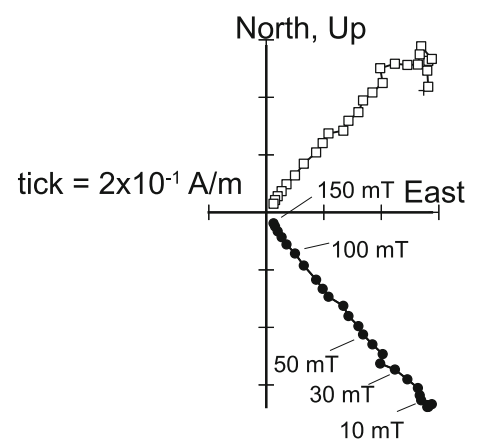

(b) $\quad \square \mathrm{Y}-\mathrm{Z}$

153-923A16R1W85-88

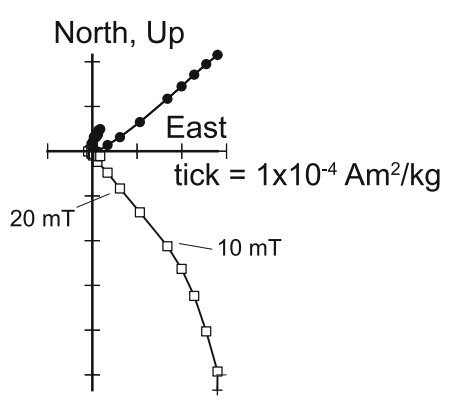

Fig. 2. Orthogonal vector plots of AF demagnetization of NRM for representative samples. Open squares are projections on the vertical plane, and filled circles are projections on the horizontal plane. Azimuthal orientation follows the ODP/IODP convention. (a) Sample with clear characteristic remanence after demagnetization of vertical downward drilling induced overprint. (b) Sample with pronounced overprint which masks characteristic remanence.

arates could not be determined. Mineral separates of a similar volume were measured to assess the relative contribution of minerals.

\section{Results}

\subsection{AF demagnetization characteristics}

Figure 2 shows orthogonal vector plots of AF demagnetization of NRM. Two remanence components were observed in all samples with varying magnitude. The lower coercivity component shows a near vertical downward direction. This component was usually demagnetized by $\sim 15$ $\mathrm{mT}$. This component is interpreted to be a drilling induced overprint. After the removal of this, a single component decaying toward the origin was observed in most samples. This is taken to be a characteristic remanence (ChRM). Except for a few samples with a very severe drilling induced overprint (Fig. 2(b)), most of the samples revealed a ChRM with a negative inclination. Together with the available age constraint of the samples, the negative inclination indicates that the samples were likely to have formed during the Matuyama interval.

\subsection{Paleointensity and anisotropy}

In total, 30 samples were measured. Five samples were accepted, 3 (out of 18) from the Leg 153 samples, and 2 (out of 12) from the Exp. 304/305 samples (Fig. 3(a) and 3(b), Table 1). Of the rejected samples, 11 samples failed to meet criteria 3 (Fig. 3(c)), 5 samples failed to meet criteria 1 (Fig. 3(d)), and 9 samples failed to meet criteria 2 (Fig. 3(e)). Some samples showed an anomalously low NRM/TRM slope relative to the paleointensity values expected from volcanic data, even though they showed little sign of laboratory alteration (Fig. 3(f)). High-temperature susceptibility data support the stability of the samples upon heating and show the dominance of near stoichiometric magnetite (Fig. 4).

For most of the successful samples, the TRM2 are close to the first TRM (Fig. 5), supporting the contention that the first TRM was indeed a total TRM. The only exception is the sample 153-923A14R1W46-48 (Fig. 5(e)). This sample shows a TRM2 much stronger than the first TRM. This may indicate that the first TRM was not a total TRM; alterna- tively, this may be due to chemical alteration. To distinguish them, I imparted another ARM (ARM3) and compared it with ARM2 (Fig. 5(f)). The AF decay curves of ARM2 and ARM3 are different, indicating the sample was altered during the second heating. After correcting the TRM2 using the difference between ARM3 and ARM2 (Rolph and Shaw, 1985), the corrected TRM2 is close to the first TRM (Fig. 5(e)). This indicates that the first TRM of the sample 153-923A14R1W46-48 was also a total TRM. Although the corrected TRM2 still shows some difference from the first TRM, this behavior should not cast any doubt on the original paleointensity experiment considering the agreement between ARM1 and ARM2.

Samples revealed a relatively strong anisotropy with an anisotropy parameter $P_{\mathrm{j}}$ (Jelinek, 1981) ranging from 1.27 to 1.49 (Table 2). The shape parameter $T_{\mathrm{j}}$ (Jelinek, 1981) ranged from oblate -0.15 to 0.73 , indicating various shapes of anisotropy from oblate to prolate.

\subsection{Rock magnetism}

Tables 3 and 4 list the hysteresis parameters for loops for bulk rock samples as well as mineral separates, and Figs. 6(a)-(c) shows representative major hysteresis. As mineral separates, plagioclase and olivine were measured on the basis of the microscopic observations (Fig. 1). Generally, the saturation remanence of olivine was stronger than that of plagioclase by $\sim 1$ order of magnitude (Table 4 ). This suggests that the magnetic properties of bulk rock samples, especially laboratory induced remanence, could be dominated by magnetite associated with the hydrothermal alteration of olivine.

On a Day plot (Day et al., 1977), the specimens were plotted over the "PSD" region (Fig. 6(b)). Apparently, there is no clear difference between samples that were successful in paleointensity experiments and those that failed. Olivine and plagioclase separates were also plotted in a similar "PSD" region (Fig. 6(b)). Those results indicate that a Day plot is not effective in predicting behavior in paleointensity experiments to exclude samples dominated by secondary magnetite.

FORC diagrams showed a different picture (Fig. 7). In FORC diagrams, the horizontal axis $\left(H_{\mathrm{c}}\right)$ is related to mi- 


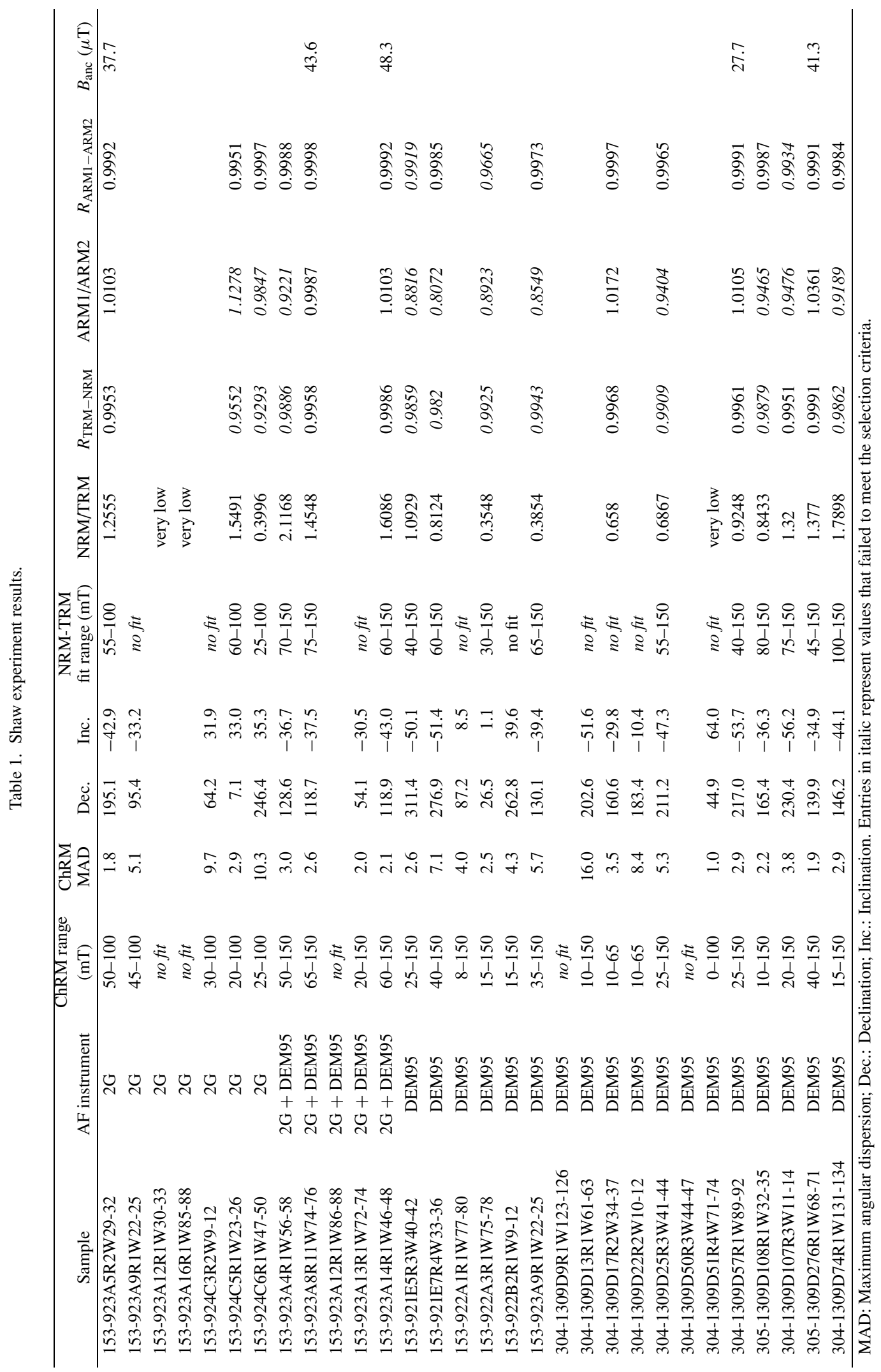


(a) $153-923 \mathrm{~A} 5 \mathrm{R} 2 \mathrm{~W} 29-32$

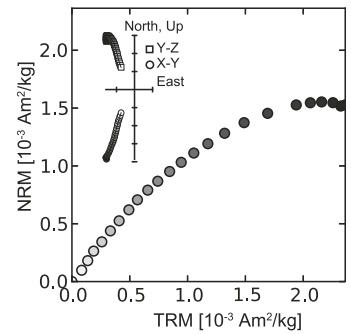

(c) 304-1309D107R3W11-14

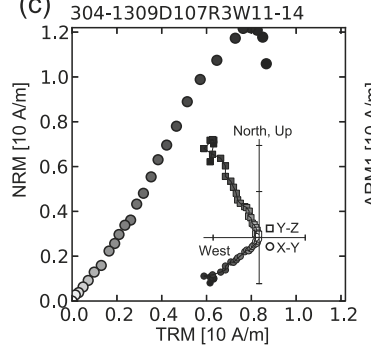

(e) 304-1304D17R2W34-37

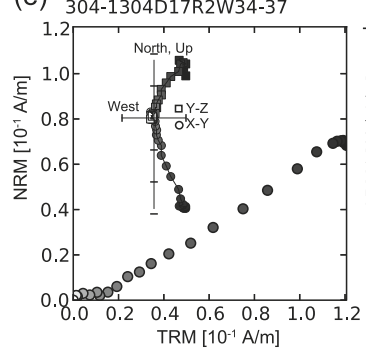

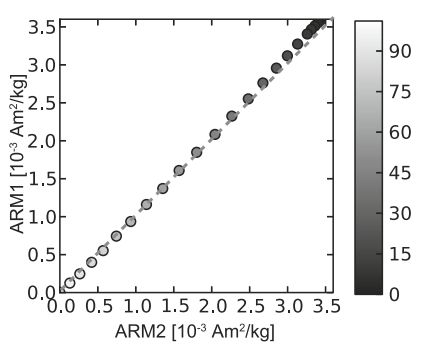
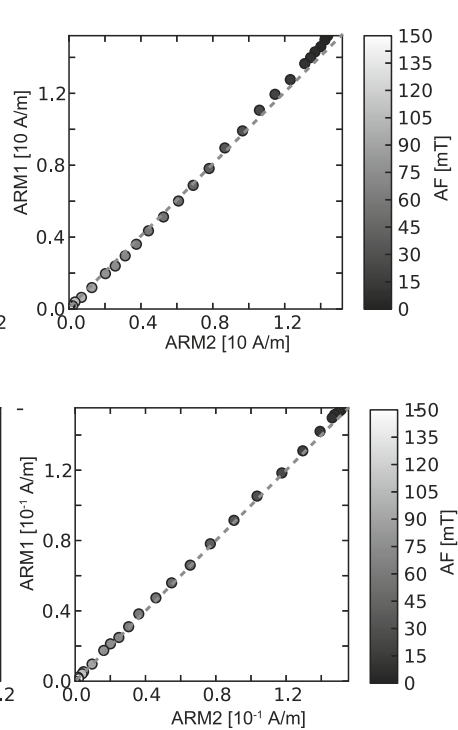

(b) 305-1309D276R1W68-71
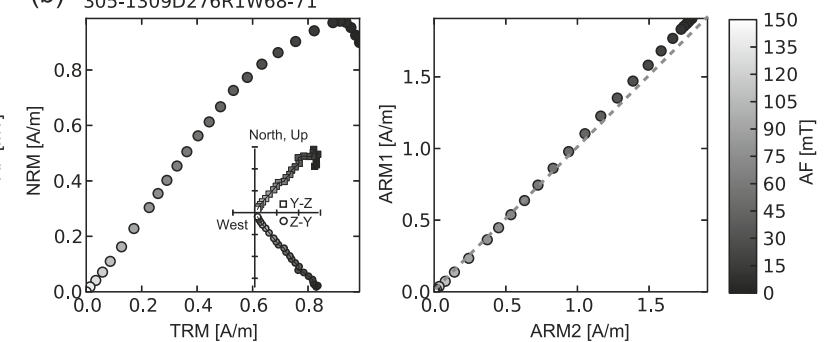

(d) 304-1304D50R3W44-47
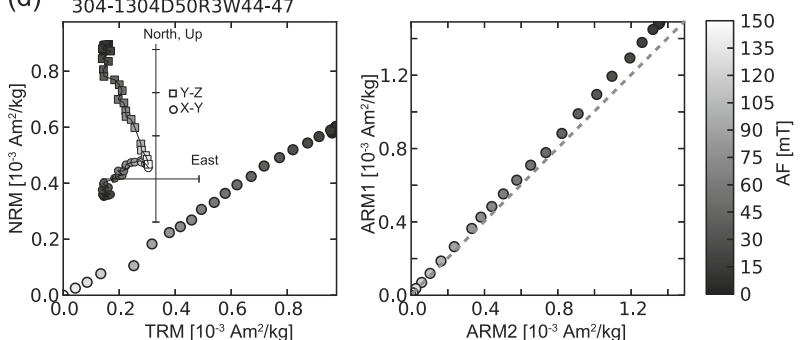

(f) 153-923A12R1W30-3
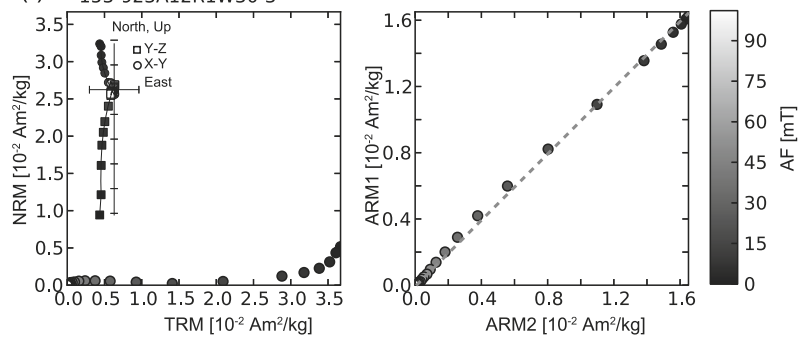

Fig. 3. Results of the Shaw paleointensity experiments. On the left are the NRM-TRM diagrams which constrain the paleointensity. The magnitude of the laboratory field used to impart a TRM was $30 \mu \mathrm{T}$. The inset of each plot shows orthogonal vector plots of AF demagnetization of NRM; squares show projections on the vertical plane, and circles show projections on the horizontal plane with an orientation following the ODP/IODP convention. On the right are the ARM1-ARM2 diagrams which check laboratory alteration. The color of each symbol shows the AF demagnetization step as indicated by the color bar. (a) Successful result from a Leg 153 sample. Demagnetization of this sample was performed by an in-line demagnetizer of cryogenic magnetometers. (b) Successful result from an Exp. 305 sample. (c) Result failed to meet slope = 1 condition in the ARM1-ARM2 plot. (d) Result failed to show characteristic remanence. (e) Result failed to show linearity in the NRM-TRM plot. (f) Result with anomalously low slope in the NRM-TRM plot. Demagnetization of this sample was performed by an in-line demagnetizer of cryogenic magnetometers.

crocoercivity, and the vertical axis $\left(H_{\mathrm{u}}\right)$ is related to the interaction field (Pike et al., 1999; Roberts et al., 2000; Carvallo et al., 2004). Successful samples (Fig. 7(a)) showed a narrow horizontal ridge along $H_{\mathrm{u}}=0$, indicating the presence of non-interacting SD particles (Newell, 2005; Egli et al., 2010). On the other hand, samples with a low NRM/TRM (Fig. 7(b)) showed a distribution with less spread along the horizontal axis and more spread along the vertical axis, indicating a greater magnetostatic interaction. The peak position was slightly shifted to the $H_{\mathrm{u}}<0$ region, which also indicates a negative mean interaction field (Roberts et al., 2000). The FORC diagrams of plagioclase separates (Fig. 7(c)) showed a clear horizontal ridge along $H_{\mathrm{u}}=0$ extending to $H_{\mathrm{c}}>150 \mathrm{mT}$ with almost no spread along the vertical axis. The FORC diagrams of olivine separates (Fig. 7(d)) were similar to those of bulk samples with a low NRM/TRM.

The domain state of the plagioclase was estimated to be PSD on the Day plot and SD on the FORC diagrams. The difference may be due to the effect of anisotropy. Theoretically, SD grains oriented at specific angles to an applied field would exhibit the major hysteresis parameters ranging from "SD" to "MD" values on the Day plot (Stoner and Wohlfarth, 1948). Although the reversal mode of actual tiny grains may not be the coherent rotation (e.g., Williams and Dunlop, 1995), angular dependence of the Day plot parameters were indeed observed for exsolved magnetite (Gee and Meurer, 2002) as well as synthetic iron rods (Milne and Dunlop, 2006). On the other hand, the theory predicts that the coercivity of a single uniaxial SD particle varies only by a factor of 2 with the angle between the field and the easy axis. The horizontal axis of the FORC diagrams can be most simply interpreted as the coercivity of single SD particles (Roberts et al., 2000). Thus, the SD signal of the FORC diagrams may be less sensitive to the grain orientation than the Day plot parameters. This explains the results of the present study where the plagioclase are more scattered on the Day plot than the olivine, while the FORC diagrams suggest that the plagioclase are much more SD like. The strong anisotropy of the plagioclase with exsolved magnetite could result in the scatter on the Day plot.

\section{Discussion}

\subsection{Effect of hydrothermal alteration on paleointensity and rock magnetism}

The FORC diagrams (Fig. 7) corroborated with microscopic observations (Fig. 1) provide strong suggestions about the microscopic origins of different behaviors in the 
(a)

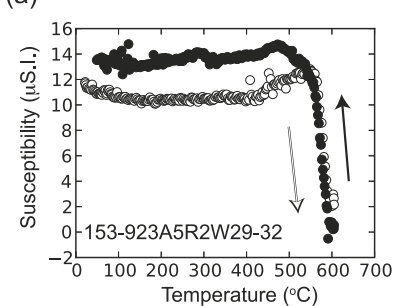

(c)

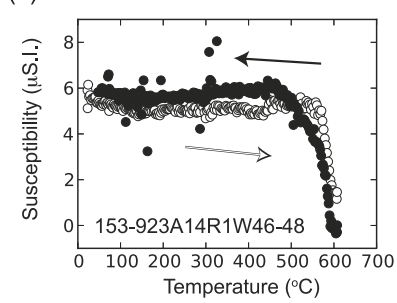

(e)

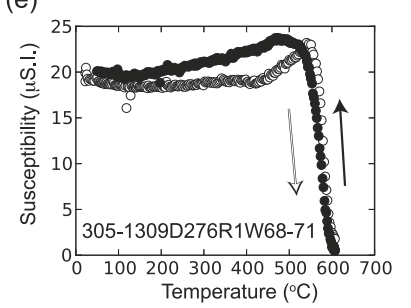

Fig. 4. High temperature susceptibility measurements. Open circles are heating curves, and filled circles are cooling curves.

Shaw paleointensity experiments. The similarity between the FORC diagrams for successful samples (Fig. 7(a)) and those for plagioclase separates (Fig. 7(c)) indicates that the successful Shaw paleointensity estimates assess the magnetite exsolved in plagioclase (Fig. 1(a)) which is composed of non-interacting SD particles. The near-ideal horizontal ridges are rare even in volcanic samples (Carvallo et al., 2006), so igneous magnetic minerals are unlikely to explain the horizontal ridges observed in successful samples. The similarity between the FORC diagram for low NRM/TRM samples (Fig. 7(b)) and those for olivine separates (Fig. 7(d)) indicates that the magnetite associated with the hydrothermal alteration of olivine (Fig. 1(b)) carries a low NRM/TRM ratio. Although the FORC diagrams indicate some magnetostatic interactions, the interaction seems to be low compared to volcanic rocks which yielded successful Thellier paleointensity results (Carvallo et al., 2006); thus, the magnetostatic interactions are unlikely to explain the low NRM/TRM. The low NRM/TRM is considered to simply reflect the low efficiency of chemical remanence (e.g., Stacy and Banerjee, 1974). These results indicate that FORC diagrams are effective in distinguishing fresh bulk samples with exsolved magnetite from samples dominated by magnetite produced by hydrothermal alteration.

\subsection{Cooling rate effect on plutonic paleointensity}

The cooling rate effect on paleointensity estimates was tested using the paleointensity results together with cooling rate estimates for some oceanic gabbros and volcanic pale- (a)

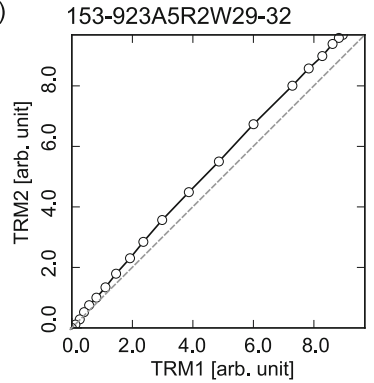

(c)

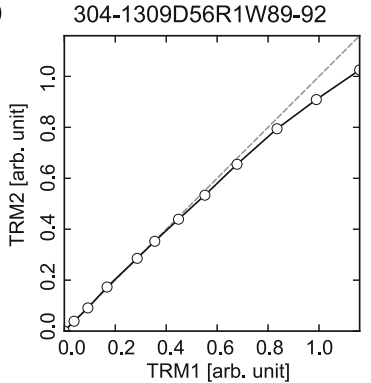

(b) $\quad$ 153-923A8R11W74-76

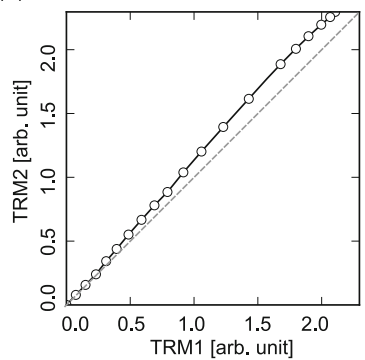

(d) 305-1309D276R1W68-71

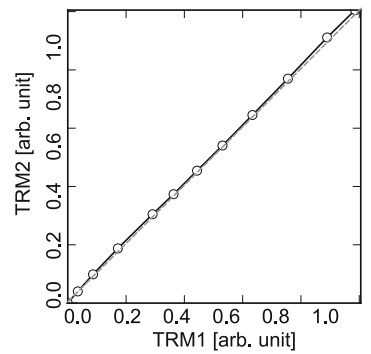

(e)

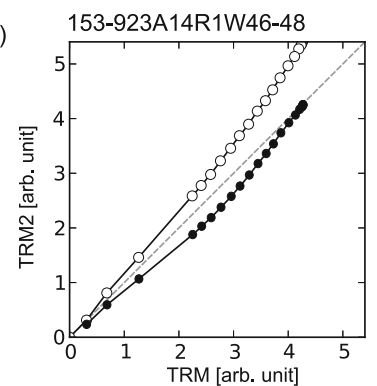

Fig. 5. Second TRM test. Filled symbols in (e) represent the comparison between TRM2 corrected by ARM with the first TRM. (f) The ARM3-ARM2 plot for the sample 153-923A14R1W46-48 showing laboratory alteration.

ointensity data. On the basis of the multiple NRM components, Gee and Meurer (2002) argued that the cooling rate of the Leg 153 gabbros around $500^{\circ} \mathrm{C}$ were on the order of $10^{2 \circ} \mathrm{C} / \mathrm{m}$.y. Other cooling rate estimates of gabbros at slow spreading ridges using elemental diffusion or simple thermal modeling gave $10^{3-4 \circ} \mathrm{C} / \mathrm{m} . \mathrm{y}$. (Coogan et al., 2007). I take the $10^{4} \mathrm{C} / \mathrm{m}$.y. as the approximate upper bound and $10^{2 \circ} \mathrm{C} / \mathrm{m}$.y. as the lower bound of the cooling rate of my samples.

I consulted volcanic paleointensity data from the PINT database (Biggin et al., 2010). The age of the Leg 153 gabbros was estimated using marine magnetic anomalies and previous paleomagnetic studies to be $\sim 0.78-1.0 \mathrm{Ma}$ (Schulz et al., 1988; Gee and Meurer, 2002). The age of the Exp. 304/305 gabbros was estimated using radioisotope dating as $\sim 1.15-1.26 \mathrm{Ma}$ (Grimes et al., 2008). On the basis of these age estimates of my gabbro samples, the volcanic paleointensity data for 0.78 to $1.3 \mathrm{Ma}$ was extracted from the database. The data was filtered using the following criteria and 69 records remained:

1) The paleointensity method is either the Thellier method (Thellier and Thellier, 1959; Coe, 1967) with partial TRM checks (accounting for 60 records), or the Shaw method with or without correction (19 records).

2) The number of specimens used to produce the paleoin- 
Table 2. Magnetic anisotropy results.

\begin{tabular}{ccrc}
\hline Sample name & $P_{\mathrm{j}}$ & \multicolumn{1}{c}{$T_{\mathrm{j}}$} & $\mathrm{RMS} / K_{\min }$ \\
\hline 153-923A8R11W74-76 & 1.49 & -0.002 & 0.133 \\
153-923A14R1W46-48 & 1.43 & 0.562 & 0.015 \\
153-923A5R2W29-32 & 1.37 & -0.150 & 0.053 \\
304-1309D57R1W89-92 & 1.27 & 0.732 & 0.025 \\
305-1309D276R1W68-71 & 1.32 & 0.334 & 0.115 \\
\hline
\end{tabular}

$P_{\mathrm{j}}$ and $T_{\mathrm{j}}$ : Jelinek's (1981) anisotropy parameters. RMS: residual mean squares of the least square fitting of an anisotropy tensor. $K_{\min }$ : minimum eigenvalue of the anisotropy tensor. The ratio RMS $/ K_{\min }$ measures the error in the tensor fitting.

Table 3. Hysteresis parameters for bulk rock samples.

\begin{tabular}{|c|c|c|c|c|}
\hline Sample & $\begin{array}{c}M_{\mathrm{s}} \\
{\left[\mathrm{mAm}^{2} / \mathrm{kg}\right]}\end{array}$ & $\begin{array}{c}M_{\mathrm{rs}} \\
{\left[\mathrm{mAm}^{2} / \mathrm{kg}\right]}\end{array}$ & $\begin{array}{c}H_{\mathrm{c}} \\
{[\mathrm{mT}]}\end{array}$ & $\begin{array}{c}H_{\mathrm{cr}} \\
{[\mathrm{mT}]}\end{array}$ \\
\hline 153-921E5R3W40-42 & 27.2 & 7.8 & 15.2 & 23.5 \\
\hline 153-922B4R1W113-115. & 1626.5 & 167.7 & 6.5 & 16.3 \\
\hline 153-923A12R1W86-88 & 606.9 & 214.2 & 20.4 & 29.5 \\
\hline 153-923A13R1W72-74 & 295.2 & 69.3 & 13.7 & 24.3 \\
\hline 153-923A14R1W46-48 & 16 & 5.8 & 30 & 58.7 \\
\hline 153-923A5R2W29-32 & 257.2 & 58.6 & 12.1 & 21 \\
\hline 153-923A8R11W74-76 & 239.5 & 72 & 16.9 & 26.1 \\
\hline 153-923A9R1W22-25 & 298.7 & 95.5 & 17.7 & 25.4 \\
\hline 153-924C3R1W75-78 & 719.2 & 95 & 8.3 & 17.4 \\
\hline 153-924C5R1W23-26 & 1939.3 & 373.3 & 13.2 & 46.7 \\
\hline 153-924C6R1W47-50 & 610.6 & 113.6 & 8.7 & 14.9 \\
\hline 304-1309D13R1W61-63 & 43.1 & 13.5 & 18.4 & 29.9 \\
\hline 304-1309D17R2W34-37 & 13.6 & 4.1 & 21.1 & 33.7 \\
\hline 304-1309D36R2W92-95 & 2 & 0.55 & 19.7 & 43.1 \\
\hline 304-1309D50R3W44-47 & 5 & 1.6 & 30.7 & 63.3 \\
\hline 304-1309D51R4W71-74 & 47.5 & 23.4 & 45.3 & 54.7 \\
\hline 304-1309D5R2W59-62 & 37.3 & 2.7 & 3.7 & 20.9 \\
\hline 304-1309D68R1W69-72 & 5.6 & 2.1 & 21.5 & 30.5 \\
\hline 304-1309D8R2W42-45 & 4.7 & 0.61 & 8.9 & 32.5 \\
\hline 304-1309D9R1W123-126 & 4 & 0.6 & 11.9 & 36.5 \\
\hline 305-1309D107R3W11-14 & 95.1 & 21.9 & 12.1 & 20.6 \\
\hline 305-1309D108R1W32-35 & 67.3 & 14.5 & 13.5 & 27 \\
\hline 305-1309D145R4W19-22 & 623.8 & 53.3 & 6.6 & 20 \\
\hline 305-1309D170R2W120-123 & 0.14 & 0.02 & 7.6 & 5 \\
\hline 305-1309D170R2W28-31 & 80.6 & 17.2 & 13.5 & 24.1 \\
\hline 305-1309D276R1W28-31 & 3014 & 195.2 & 5.1 & 15.7 \\
\hline
\end{tabular}

Table 4. Hysteresis parameters for mineral separates.

\begin{tabular}{ccccc}
\hline Sample & $M_{\mathrm{S}}\left[10^{-9} \mathrm{Am}^{2}\right]$ & $M_{\mathrm{rs}}\left[10^{-9} \mathrm{Am}^{2}\right]$ & $H_{\mathrm{c}}[\mathrm{mT}]$ & $H_{\mathrm{cr}}[\mathrm{mT}]$ \\
\hline olivine-1 & 823.6 & 283.8 & 17.7 & 26.7 \\
olivine-2 & 922.1 & 261.9 & 15.3 & 25.5 \\
olivine-3 & 1581.6 & 547.4 & 17.5 & 25.9 \\
plagioclase-1 & 55.2 & 19.5 & 27.5 & 51.1 \\
plagioclase-2 & 40.0 & 7.2 & 16.3 & 43.5 \\
plagioclase-3 & 116.9 & 25.2 & 16.4 & 35 \\
plagioclase-4 & 60.0 & 21.5 & 28.7 & 57.8 \\
\hline
\end{tabular}

tensity value is at least 3 .

3) The standard deviation of the paleointensity is not greater than $25 \%$.

4) The magnetic polarity is known and not transitional. records was $6.3 \pm 0.73\left[10^{22} \mathrm{Am}^{2}\right]$, where the uncertainty is given as a $95 \%$ confidence interval (Table 5).

The paleointensity estimates from oceanic gabbros are converted to a virtual axial dipole moment (VADM) using the present day latitude of the drilling Sites $\left(24^{\circ} \mathrm{N}\right.$ for the

The mean virtual dipole moment (VDM) of the 69 Leg 153 samples and $30^{\circ} \mathrm{N}$ for the Exp. 304/305 samples). 
(a)

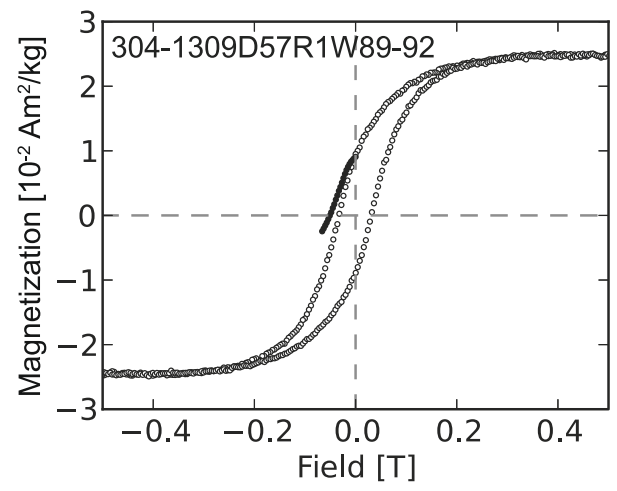

(c)

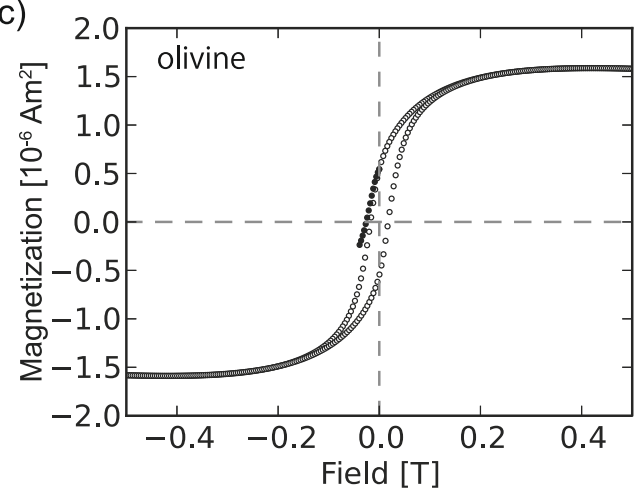

(b)

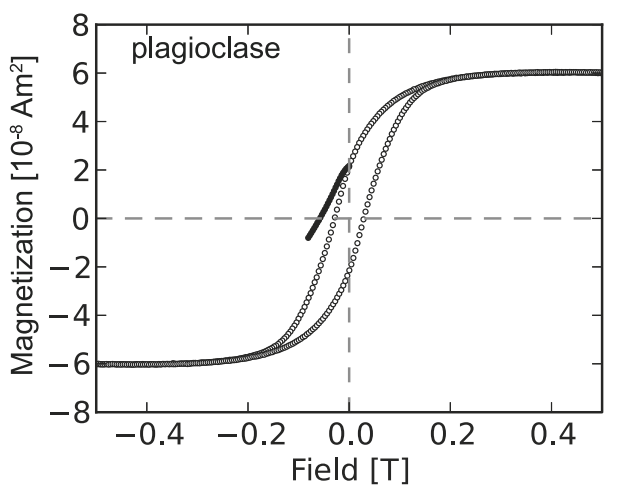

(d)

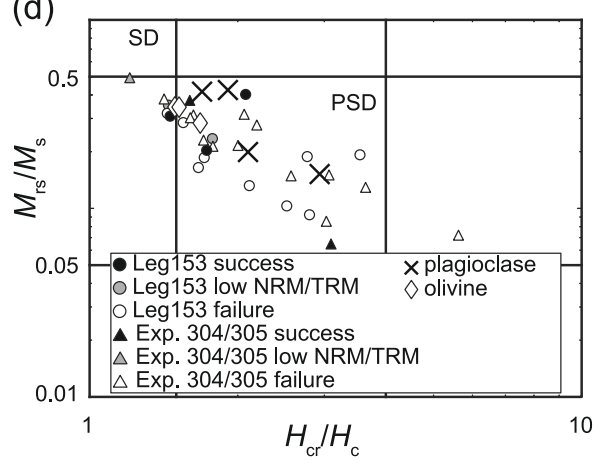

Fig. 6. Analysis of major magnetic hysteresis parameters of bulk rock samples and mineral separates. (a)-(c) Example of slope-corrected major hysteresis loop (open circles) and back field demagnetization of saturation remanence (filled circles) of (a) a bulk sample, (b) a plagioclase separate, and (c) an olivine separate. (d) Summary of magnetic hysteresis parameters on a Day plot. Black circles are Leg 153 samples with successful paleointensity results, gray circles are Leg 153 samples with a low NRM/TRM, open circles are Leg 153 samples that failed in the paleointensity experiments, black triangles are Exp. 304/305 samples with successful paleointensity results, gray triangles are Exp. 304/305 samples with a low NRM/TRM, open triangles are Exp. 304/305 samples that failed in the paleointensity experiments, crosses are plagioclase separates, and diamonds are olivine separates.

Table 5. Paleointensity results.

\begin{tabular}{cccccc}
\hline Sample & Lat & $H_{\text {anc }}[\mu \mathrm{T}]$ & $H_{\text {anc_anis }}[\mu \mathrm{T}]$ & ${\text { VADM }\left[10^{22} \mathrm{Am}^{2}\right]}^{\mathrm{VADM}_{\text {anis }}\left[10^{22} \mathrm{Am}^{2}\right]}$ \\
\hline 153-923A8R11W74-76 & 23.5 & 43.6 & 44.2 & 9.4 & 10.4 \\
153-923A14R1W46-48 & 23.5 & 48.3 & 44.9 & 8.5 & 9.7 \\
153-923A5R2W29-32 & 23.5 & 37.7 & 35.8 & 5.5 & 5.7 \\
304-1309D57R1W89-92 & 30.2 & 27.7 & 25.5 & 8.2 & 9.0 \\
305-1309D276R1W68-71 & 30.2 & 41.3 & 45.7 & $8.3 \pm 2.3$ & $8.2 \pm 2.1$ \\
Average & & & & $6.3 \pm 0.73$ (VDM) \\
Data from PINT* & & & & \\
\hline
\end{tabular}

* see text for data selection criteria.

Lat: Present day latitude. $H_{\text {anc }}$ : estimated paleointensity. $H_{\text {anc_anis }}$ : paleointensity after anisotropy correction. VADM anis $_{\text {VADM after }}$ anisotropy correction.

The oceanic gabbro layer formed at slow-spreading ridges is considered to be tilted due to detachment faulting (Garcés and Gee, 2007; Morris et al., 2009; MacLeod et al., 2011), and their present remanence inclinations may not reflect the geomagnetic inclination at the time of remanence acquisition. I obtained the mean VADM of $8.2 \pm 2.1\left[10^{22} \mathrm{Am}^{2}\right]$ after the anisotropy correction (Selkin et al., 2000); before the correction, the mean was $8.3 \pm 2.3\left[10^{22} \mathrm{Am}^{2}\right]$ (Table 5). It should be noted that the temperature of magnetite exsolution is not well constrained for plagioclase. If this is lower than the Curie temperature of magnetite, the paleointensity estimate may not be accurate (Stacy and Banerjee, 1974;
Fabian, 2009). In such a case, the exsolved magnetite is likely to acquire a classical grain growth thermochemical remanence, which is less efficient than TRM (Stacy and Banerjee, 1974); thus, the VADM estimated here may be viewed as a lower bound.

Using cooling rate estimates for oceanic gabbros (Gee and Meurer, 2002; Coogan et al., 2007), the formula given by Halgedahl et al. (1980) for SD magnetite predicts that the cooling rate effect results in a $37-46 \%$ paleointensity overestimation in my samples. The present data are generally consistent with this prediction (Fig. 8). The mean paleointensity estimates from the gabbro sam- 
(a) 304-1309D57R1W89-92

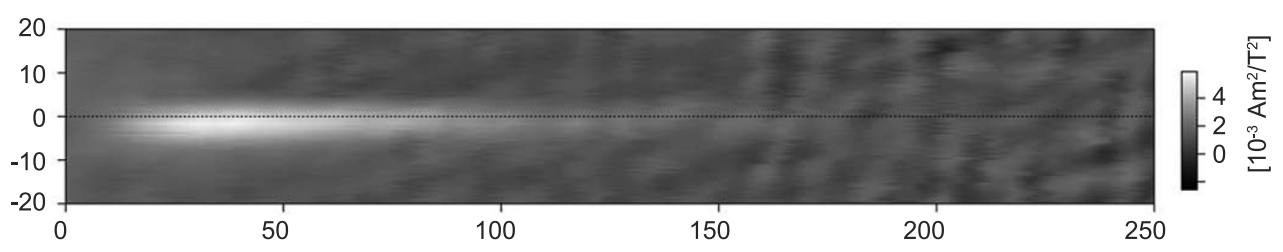

(b) 153-923A12R1W30-33

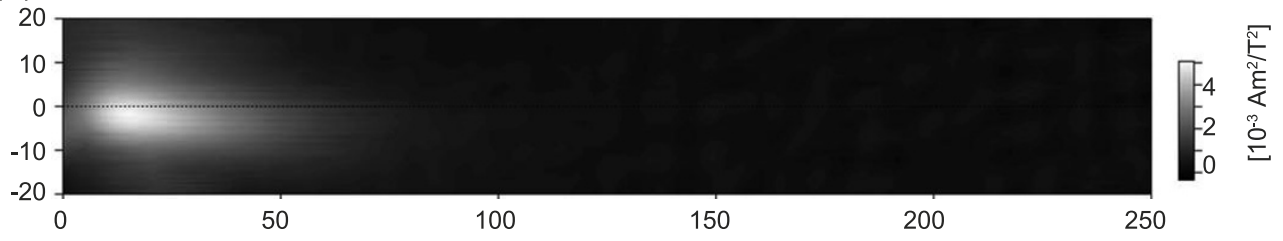

(c) plagioclase

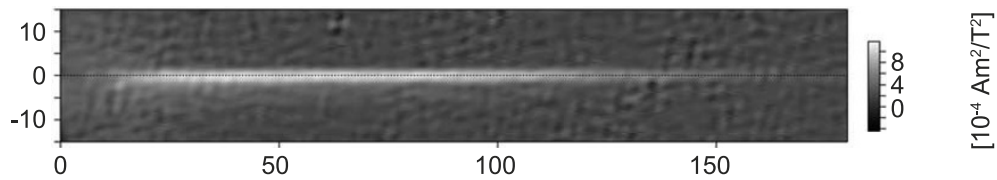

(d) olivine

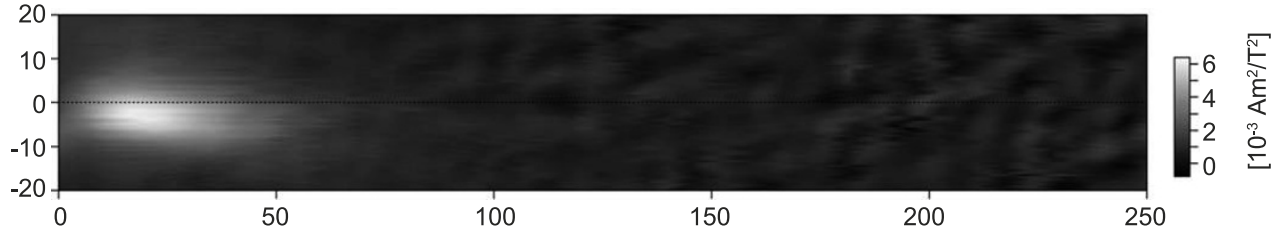

Fig. 7. FORC diagrams of bulk rock samples and mineral separates. All diagrams are calculated using a smoothing factor of 3. (a) Sample that was successful in the paleointensity experiments showing a narrow horizontal ridge along $H_{\mathrm{u}}=0$. (b) Sample that revealed a low NRM/TRM in the paleointensity experiments showing a concentrated peak. (c) Plagioclase crystal showing a narrow horizontal ridge along $H_{\mathrm{u}}=0$. (d) Olivine crystal showing a concentrated peak.

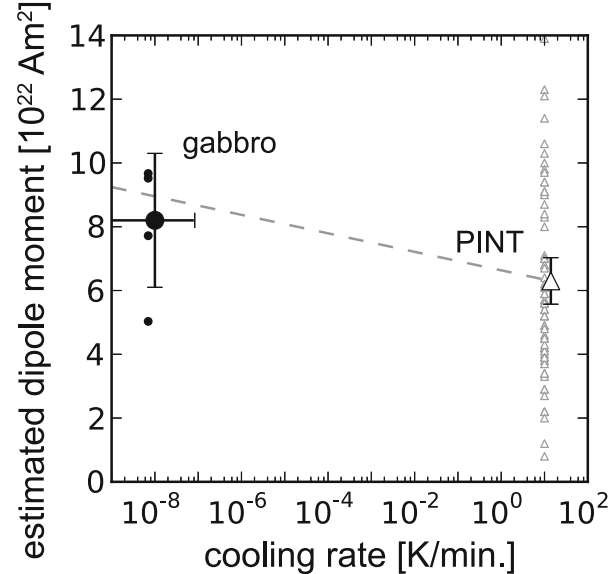

Fig. 8. Analysis of the cooling rate effect on paleointensity estimates from gabbros and volcanic data in the PINT database. Open triangles are volcanic data (small symbols are cooling unit means, and the large symbol is the overall mean with a $95 \%$ confidence limit). Filled circles are gabbro data (small symbols are the results of individual samples, and a large symbol is the mean paleointensity with $95 \%$ confidence limit for estimated VADM. The horizontal error bar indicates the plausible range of the cooling rate; see the text for a discussion). The dashed line represents the theoretical paleointensity overestimate (Halgedahl et al., 1980) with respect to the mean VDM calculated from the PINT data. ples $\left(8.2\left[10^{22} \mathrm{Am}^{2}\right]\right)$ is higher than the mean VDM from volcanic data $\left(6.3\left[10^{22} \mathrm{Am}^{2}\right]\right)$ by $30 \%$.

The present study has revealed that exsolved magnetite in oceanic gabbros provide the expected paleointensity, and that FORC analysis is effective to find samples dominated by exsolved magnetite. Exsolved magnetite seems to be common in oceanic gabbros (Davies, 1981), and it has been also reported from continental plutonic and metamorphic rocks (e.g., Selkin et al., 2000; Usui et al., 2006; Wenk et al., 2011). In particular, oceanic gabbros of various geologic ages are preserved on land as ophiolites, and some of them have been successfully investigated for paleointensity (Granot et al., 2007). The present results form the basis for further paleointensity investigation of such materials.

\section{Conclusions}

1) Magnetite exsolved in plagioclase show distinct FORC diagrams with a pronounced central ridge. This is in sharp contrast to most igneous rocks (Carvallo et al., 2006) and to the altered olivine. Therefore, FORC diagrams can be a very effective pre-selection tool for paleointensity studies on plutonic rocks which contain exsolved magnetite.

2) The mean paleointensity estimates from the gabbro samples $\left(8.2\left[10^{22} \mathrm{Am}^{2}\right]\right)$ is higher than the mean VDM from volcanic data $\left(6.3\left[10^{22} \mathrm{Am}^{2}\right]\right)$ by $30 \%$, being consistent with the prediction of simple SD theory 
in my oceanic gabbro samples. A greater sample number is necessary for a quantitative assessment.

3) Paleointensity investigations of oceanic gabbros complemented by FORC analysis will be an effective strategy to constrain the time evolution of the geodynamo.

Acknowledgments. This study used samples provided by the Ocean Drilling Program (ODP) and Integrated Ocean Drilling Program (IODP). I thank Yuhji Yamamoto for access to the AGFM. I would also like to thank Kazue Tsuchida for help in the laboratory, Toshiya Kanamatsu for encouragement, and John Tarduno for critical discussions during the early stage of the study. I am grateful to an anonymous reviewer and Yuhji Yamamoto for constructive reviews.

\section{References}

Biggin, A., A. McCormack, and A. Roberts, Paleointensity database updated and upgraded, EOS, 91, 15, 2010.

Blackman, D. K., B. Ildefons, B. E. John, Y. Ohara, D. J. Miller, C. J. MacLeod, and Expedition 304/305 Scientists, Proceedings of the Integrated Ocean Drilling Program Volume 304/305, Integrate Ocean Drilling Program Management International Inc., Texas, doi:10.2204/iodp.proc.304305.2006, 2006.

Blackman, D. K., B. Ildefonse, B. E. John, Y. Ohara, D. J. Miller, N. Abe, M. Abratis, E. S. Andal, M. Andreani, S. Awaji, J. S. Beard, D. Brunelli, A. B Charney, D. M. Christie, J. Collins, A. G. Delacour, H. Delius, M. Drouin, F. Einaudi, J. Escartín, B. R. Frost, G. Früh-Green, P. B. Fryer, J. S. Gee, M. Godard, C. B. Grimes, A. Halfpenny, H.E. Hansen, A. C. Harris, A. Tamura, N. W. Hayman, E. Hellebranc, T. Hirose, J. G. Hirth, S. Ishimaru, K. T. M. Johnson, G. D. Karner, M. Linek, C. J. MacLeod, J. Maeda, O. U. Mason, A. M. McCaig, K. Michibayashi, A. Morris, T. Nakagawa, T. Nozaka, M. Rosner, R. C. Searle, G. Suhr, M. Tominaga, A. von der Handt, T. Yamasaki, and $\mathrm{X}$. Zhao, Drilling constraints on lithospheric accretion and evolution at Atlantis Massif, Mid-Atlantic Ridge, $30^{\circ} \mathrm{N}$, J. Geophys. Res., 116(B7), B07103, doi:10.1029/2010JB007931, 2011.

Borradaile, G. J. and M. Stupavsky, Anisotropy of magnetic susceptibility: Measurement schemes, Geophys. Res. Lett., 22, 1957-1960, doi:10.1029/95GL01910, 1995.

Cannat, M., J. A. Karson, D. J. Miller, S. M. Agar, J. Barling, J. F. Casey, G. Ceuleneer, Y. Dilek, J. Fletcher, N. Fujibayashi, L. Gaggero, J. S. Gee, S. D. Hurst, D. S. Kelley, P. D. Kempton, R. M. Lawrence, V. Marchig, C. Mutter, K. Niida, K. Rodway, D. K. Ross, C. Stephens, C.-D. Werner, and H. Whitechurch, Proceedings of the Ocean Drilling Program Initial Report 153, Ocean Drilling Program, Texas, doi:10.2973/odp.proc.ir.153., 1995.

Carvallo, C., Ö. Özdemir, and D. J. Dunlop, First-order reversal curve (FORC) diagrams of elongated single-domain grains at high and low temperatures, J. Geophys. Res., 119, B04105, doi:10.1029/2003JB2539, 2004.

Carvallo, C., A. P. Roberts, R. Leonhardt, C. Laj, C. Kissel, M. Perrin, and $\mathrm{P}$. Camps, Increasing the efficiency of paleointensity analyses by selection of samples using first-order reversal curve diagrams, J. Geophys. Res., 111, B12103, doi:10.1029/2005JB004126, 2006.

Chauvin, A., Y. Garcia, P. Lanos, and F. Laubenheimer, Paleointensity of the geomagnetic field recovered on archaeomagnetic sites from France, Phys. Earth Planet. Inter., 120, 111-136, doi:10.1016/S00319201(00)00148-5, 2000.

Coe, R., The determination of paleointensities of the Earth's magnetic field with emphasis on mechanisms which could cause non-ideal behavior in Thellier's method, J. Geomag. Geoelectr., 19, 157-179, 1967.

Coe, R. and C. S. Grommé , A comparison of three methods of determining geomagnetic paleointensities, J. Geomag. Geoelectr., 25, 415-435, 1973.

Coogan, L. A., G. R. T. Jenkin, and R. N. Wilson, Contrasting cooling rates in the lower oceanic crust at fast- and slow-spreading ridges, J. Petrol., 48, 2211-2231, doi:10.1093/petrology/egm057, 2007.

Cottrell, R. D. and J. A. Tarduno, Geomagnetic paleointensity derived from single plagioclase crystals, Earth Planet. Sci. Lett., 169, 1-5, doi:10.1016/S0012-821X(99)0068-0, 1999.

Davies, K. E., Magnetite rods in plagioclase as the primary carrier of stable NRM in ocean floor gabbros, Earth Planet. Sci. Lett., 55, 190-198, 1981.
Day, R., M. D. Fuller, and V. A. Schmidt, Hysteresis properties of titanomagnetites: Grain size and compositional dependence, Phys. Earth Planet. Inter., 13, 260-267, 1977.

Dodson, M. and E. McClelland-Brown, Magnetic blocking temperatures of single domain grains during slow cooling, J. Geophys. Res., 85, 26252637, 1980.

Donadini, F., S. Å. Elming, L. Tauxe, and U. Hålenius, Paleointensity determination on a 1.786 Ga old gabbro from Hoting, Central Sweden, Earth Planet. Sci. Lett., 309, 234-248, doi:10.1016/j.epsl.2011.07.005, 2011.

Egli, R., A. P. Chen, M. Winklhofer, K. P. Kodama, and C.-S. Horng, Detection of noninteracting single domain particles using first-order reversal curve diagrams, Geochem. Geophys. Geosyst., 11, Q01Z11, doi:10.1029/2009GC002916, 2010.

Fabian, K., Thermochemical remanence acquisition in single-domain particle ensembles: A case for possible overestimation of the geomagnetic paleointensity, Geochem. Geophys. Geosyst., 10, Q06Z03, doi:10.1029/2009GC002420, 2009.

Feinberg, J. M., H.-R. Wenk, P. R. Renne, and G. R. Scott, Exsolved magnetite inclusions in silicates: features determining their remanence behavior, Geology, 33, 513-516, 2005.

Feinberg, J. M., R. J. Harrison, R. E. Dunin-Borkowski, T. Kasama, G. R. Scott, and P. R. Renne, The influence of nanoscale microstructure on the remanence properties of clinopyroxene-hosted titanomagnetite inclusions: An electron holography study, J. Geophys. Res., 111, B12S15, doi:10.1029/2006JB004498, 2006.

Ferk, A., F. W. V. Aulock, R. Leonhardt, K.-U. Hess, and D. B. Dingwell, A cooling rate bias in paleointensity determination from volcanic glass: An experimental demonstration, J. Geophys. Res., 115, B08102, doi:10.1029/2009JB006964, 2010.

Fox, J. and M. Aitken, Cooling-rate dependence of thermoremanent magnetization, Nature, 462-463, 1980.

Garcés, M. and J. S. Gee, Paleomagnetic evidence of large footwall rotations associated with low-angle faults at the Mid-Atlantic Ridge, Geology, 35, 279-282, doi:10.1130/G23165A.1, 2007.

Gee, J. S and W. P. Meurer, Slow cooling of middle and lower oceanic crust inferred from multicomponent magnetizations of gabbroic rocks from the Mid-Atantic Ridge south of the Kane fracture zone (MARK) area, J. Geophys. Res., 107(B7), 2137, doi:10.1029/2000JB000062, 2002.

Gee, J. S., R. M. Lawrence, and S. D. Hurst, Remanence characteristics of gabbros from the MARK area: Implications for crustal magnetization, in Proceedings of the Ocean Drilling Program Scientific Results 153, edited by J. A. Karson, M. Cannat, D. J. Miller, and D. Elthon, pp. 429-436, Ocean Drilling Program, Texas, doi:102973/odp.proc.sr.153.042.1997, 1995.

Genevey, A. and Y. Gallet, Intensity of the geomagnetic field in western Europe over the past 2000 years: New data from ancient French pottery, J. Geophys. Res., 107(B11), 2285, doi:10.1029/2001JB000701, 2002.

Granot, R., L. Tauxe, J. S. Gee, and H. Ron, A view into the Cretaceous geomagnetic field from analysis of gabbros and submarine glasses, Earth Planet. Sci. Lett., 256, 1-11, 2007.

Grimes, G. B., B. E. John, and J. L. Wooden, Protoracted construction of gabbroic crust at a slow-spreading ridge: Constraints from ${ }^{206} \mathrm{~Pb} /{ }^{238} \mathrm{U}$ zircon ages from Atlantis Massif and IODP Hole 1309 (30 N, MAR), Geochem. Geophys. Geosyst., 9, Q08012, doi:10.1029/2008GC002063, 2008.

Halgedahl, S., R. Day, and M. Fuller, The effect of the cooling rate on the intensity of weak field TRM in single domain magnetite, J. Geophys. Res., 85, 3690-3698, 1980.

Harrison, R. J. and J. M. Feinberg, FORCinel: An improved algorithm for calculating first-order reversal curve distributions using locally weighted regression smoothing, Geochem. Geophys. Geosyst., 9, Q05016, doi:10.1029/2008GC001987, 2008.

Jelinek, V., Characterization of the magnetic fabric of rocks, Tectonophysics, 79, 63-67, 1981.

Kikawa, E. and K. Ozawa, Contribution of oceanic gabbros to seafloor spreading magnetic anomalies, Science, 258, 796-799, 1992.

Kono, M., Reliability of palaeointensity methods using alternating field demagnetization and anhysteretic remanence, Geophys. J. R. Astron. Soc., 54, 241-261, doi:10.1111/j.1365-246X.1978.tb04258.x, 1978.

Leonhardt, R., J. Matzka, A. Nichols, and D. Dingwell, Cooling rate correction of paleointensity determination for volcanic glasses by relaxation geospeedometry, Earth Planet. Sci. Lett., 243, 282-292, 2006.

MacLeod, C. J., J. Carlut, J. Escartin, H. Horen, and A. Morris, Quantitative constraint on footwall rotations at the $15^{\circ} 45^{\prime} \mathrm{N}$ oceanic core complex, Mid-Atlantic Ridge: Implication for oceanic detach- 
ment fault processes, Geochem. Geophys. Geosyst., 12, Q0AG03, doi:10.1029/2011GC003503, 2011.

Milne, G. and D. J. Dunlop, Angular variation of the magnetic properties and reversal mode of aligned single-domain iron nanoparticles, J. Geophys. Res., 111, B12S08, doi:10.1029/2006JB004530, 2006.

Morris, A., J. S. Gee, N. Pressling, B. E. John, C. J. MacLeod, C. B. Grimes, and R. C. Searle, Footwall rotation in an oceanic core complex quantified using reoriented Integrated Ocean Drilling Program core samples, Earth Planet. Sci. Lett., 287, 217-228, doi:10.1016/j.epsl.2009.08.007, 2009.

Newell, A. J., A high-precision model of first-order reversal curve (FORC) functions for single-domain ferromagnets with uniaxial anisotropy, Geochem. Geophys. Geosyst., 6, Q05010, doi:10.1029/2004GC000877, 2005.

Oishi, Y., H. Tsunakawa, N. Mochizuki, Y. Yamamoto, K.-I. Wakabayashi, and H. Shibuya, Validity of the LTD-DHT Shaw and Thellier paleointensity methods: a case study of the Kilauea 1970 lava, Phys. Earth Planet. Inter., 149, 243-257, doi:10.1016/j.pepi.2004.10.009, 2005.

Pariso, J. E. and H. P. Johnson, Do lower crustal rocks record reversals of the Earth's magnetic field? Magnetic properties of oceanic gabbros from Ocean Drilling Program Hole 735B, J. Geophys. Res., 98, 1601316032, doi:10.1029/93JB00933, 1993.

Pike, C. R., A. P. Roberts, and K. L. Verosob, Characterizing interactions in fine magnetic particle systems using first order reversal curves, J. Appl. Phys., 85, 6660-6667, 1999.

Roberts, A. P., C. R. Pike, and K. L. Verosob, FORC diagrams: A new tool for characterizing the magnetic properties of natural samples, $J$. Geophys. Res., 105, 28461-28475, 2000.

Rolph, T. C. and J. Shaw, A new method of paleofield magnitude correction for thermally altered samples and its application to Lower Carboniferous lavas, Geophys. J. R. Astron. Soc., 80, 773-781, 1985.

Schulz, N. J., R. S. Detrick, and S. P. Miller, Two- and three dimensional inversions of magnetic anomalies in the MARK area (Mid-Atlantic Ridge $23^{\circ} \mathrm{N}$ ), Mar. Geophys. Res., 10, 41-57, 1988.

Selkin, P. A., J. S. Gee, L. Tauxe, W. P. Meurer, and A. J. Newell, The effect of remanence anisotropy on paleointensity estimates: A case study from Archean Stillwater Complex, Earth Planet. Sci. Lett., 183, 403-416, 2000.

Selkin, P. A, J. S. Gee, W. P. Meurer, and S. R. Hemming, Paleointensity record from the $2.7 \mathrm{Ga}$ Stillwater Complex, Montana, Geochem. Geophys. Geosyst., 9, Q12023, doi:10.1029/2008GC001950, 2008.

Shaw, J., A new method of determining the magnitude of the paleomagnetic field. Application to five historic lavas and five archaeological samples, Geophys. J. R. Astron. Soc., 76, 637-651, 1974.

Stacey, F. D. and S. K. Banerjee, The Physical Principles of Rock Magnetism, 195 pp., Elsevier, New York, 1974.

Stoner, E. C. and E. P. Wohlfarth, A mechanism of magnetic hysteresis in heterogeneous alloys, Phil. Trans. R. Soc. Lond. Ser. A, 240, 599-642, doi:10.1098/rsta.1948.0007, 1948.

Tarduno, J. A., R. D Cottrell, and A. V. Smirnov, The paleomagnetism of single silicate crystals: Recording the geomagnetic field during mixed polarity intervals, superchrons and inner core growth, Rev. Geophys., 44, RG1002, 2006.

Tarduno, J. A., R. D. Cottrell, M. K. Watkeys, and D. Bauch, Geomagnetic field strength 3.2 billion years ago recorded by single silicate crystals, Nature, 446, 657-660, doi:10.1038/nature05667, 2007.

Thellier, E. and O. Thellier, Sur l'intensité du champ magnétique terrestre dans le passé historique et géologique, Annales de Géophysique, 15, 285-376, 1959.

Trindade, R. I. F., J.-L. Buchez, O. Bolle, A. Nédélec, A. Peschler, and F. Poitrasson, Secondary fabrics revealed by remanence anisotropy: methodological study and examples from plutonic rocks, Geophys. $J$. Int., 147, 310-318, 2001.

Usui, Y. and N. Nakamura, Nonlinear thermoremanence corrections for Thellier paleointensity experiments on single plagioclase crystals with exsolved magnetites: A case study for the Cretaceous Superchron, Earth Planets Space, 61, 1327-1337, 2009.

Usui, Y. and S. Yamazaki, Salvaging primary remanence from hydrothermally altered oceanic gabbros in the Oman ophiolite: A selective destructive demagnetization approach, Phys. Earth Planet. Inter., 181, 111, doi:10.1016/j.pepi.2010.04.008, 2010.

Usui, Y., N. Nakamura, and Y. Yoshida, Magnetite microexsolutions in silicate and magmatic flow fabric of the Goyozan granitoid (NE Japan): Significance of partial remanence anisotropy, J. Geophys. Res., 111, B11101, doi:10.1029/2005JB004183, 2006.

Wenk, H.-R., K. Chan, and R. Smith, Morphology and microstructure of magnetite and ilmenite inclusions in plagioclase from Adirondack anorthositic gneiss, Am. Mineral., 96, 1316-1324, doi:10.2138/am.2011.3716, 2011.

Williams, W. and D. J. Dunlop, Simulation of magnetic hysteresis in pseudo-single-domain grains of magnetite, J. Geophys. Res., 100, 3859871, doi:10.1029/94JB02878, 1995.

Winklhofer, M., K. Fabian, and F. Heider, Magnetic blocking temperatures of magnetite calculated with a three-dimensional micromagnetic model, J. Geophys. Res., 102(B10), 22695-22709, doi:10.1029/97JB01730, 1997.

Yamamoto, Y. and H. Tsunakawa, Geomagnetic field intensity during the last 5 Myr: LTD-DHT Shaw paleointensities from volcanic rocks of the Society Islands, French Polynesia, Geophys. J. Int., 162, 79-114, doi:10.1111/j.1365-246X.2005.02651.x, 2005.

$\mathrm{Yu}, \mathrm{Y}$., Importance of cooling rate dependence of thermoremanence in paleointensity determination, J. Geophys. Res., 116, B09101, doi:10.1029/2011JB008388, 2011

Zhao, X. and M. Tominaga, Paleomagnetic and rock magnetic results from lower crustal rocks of IODP Site U1309: Implication for thermal and accretion history of the Atlantis Massif, Tectonophysics, 474, 435-448, doi:10.1016/j.tecto.2009.04.017, 2009.

Y. Usui (e-mail: yoichi@jamstec.go.jp) 